\title{
BIO(NECRO)POLÍTICA DA MINERAÇÃO: QUANDO O DESASTRE ATINGE O CORPO-TERRITÓRIO*
}

\author{
Maria de Oliveira Penido \\ UFF - Universidade Federal Fluminense
}

\begin{abstract}
Resumo
O artigo aborda o desastre da Samarco, como processo, vivenciado desde a escala do corpo pelos atingidos. A partir de uma bio(necro)política da mineração, com base em relatórios produzidos e em alguns relatos, destacamos os problemas de saúde vivenciados em Mariana e Barra Longa-MG em decorrência do desastre. Para além das doenças, o "sofrimento social" dos atingidos é engendrado nos processos de desterritorialização e na constante deslegitimação de suas narrativas e denúncias.
\end{abstract}

Palavras-chave: Desastre, Bio(necro)política, Doenças
Resumen

El artículo aborda el desastre de Samarco, como proceso, vivido desde la escala del cuerpo por los afectados. A partir de una bio(necro)política de la minería, con base en informes producidos y en algunos relatos, destacamos los problemas de salud vivenciados en Mariana y Barra Longa-MG, como consecuencia del desastre. Además de las enfermedades, el "sufrimiento social" de los afectados es engendrado en los procesos de desterritorialización y en la constante deslegitimación de sus narrativas y denuncias.

Palabras clave: Desastre, Bio(necro)política, Enfermedades.

\section{Introdução}

tão alegada e naturalizada "vocação mineradora" de Minas Gerais encobre as estruturas de poder que sustentam a apropriação dos recursos minerais no estado desde os primórdios da colonização europeia, possibilitando o avanço da mineração e sua reprodução como proposta hegemônica de desenvolvimento.

Para Altvater (1995), "desenvolvimento" é, necessariamente, consumo de bens naturais e produção sistemática de entropia ${ }^{1}$, existindo, conforme o autor, uma imposição ecológica ao desenvolvimento ilimitado, na medida em que deflagra mudanças irreversíveis na natureza, base material da riqueza e da vida. Do ponto de vista ecológico, a racionalidade economicista reportase aos bens comuns, às reservas energéticas e minerais, enquanto inputs; e ao meio ambiente, enquanto depósito para as emissões e rejeitos industriais, enquanto output (ALTVATER, 1995).

\footnotetext{
* O presente trabalho foi realizado com apoio da Coordenação de Aperfeiçoamento de Pessoal de Nível Superior - Brasil (CAPES) - Código de Financiamento 001. This study was financed in part by the Coordenação de Aperfeiçoamento de Pessoal de Nível Superior - Brasil (CAPES) - Finance Code 001.

${ }^{1}$ Toda transformação que envolve matéria ou energia gera um aumento de entropia. A_entropia nos remete, portanto, à irreversível transformação da matéria e à degradação da energia (ALTVATER, 1995).
} 
De acordo com Malerba (2012, pp. 13-14), a estrutura do setor mineral global está organizada, historicamente, de forma que as fases mais degradantes e intensivas na utilização de recursos naturais permanecem nos países ditos periféricos (extração de minério de ferro e produção de semiacabados), enquanto "a fase menos poluente [...] e com produtos de maior valor agregado" encontra-se nos países centrais. Nessa troca ecológica e economicamente desigual, como bem mostra Altvater (1995), o preço da riqueza de alguns é a miséria social e ambiental de outros.

As desigualdades advindas da divisão internacional do trabalho, como divisão simultânea e assimétrica da natureza (CORONIL, 2005), das forças monopolistas espacialmente articuladas e das práticas extorsivas vinculadas aos fluxos de capital adquirem expressão espacial (HARVEY, 2005), reconfigurando e destruindo territórios, produzindo riscos e desastres, intensificados e expandidos frente à racionalidade neoliberal. Nessa perspectiva, a mineração tem transformado os territórios, ao mesmo tempo, em provedores por excelência de riquezas naturais e em repositório de perigos e desastres, inerentes à atividade (ARÁOZ, 2009; 2014).

Um dos maiores desastres envolvendo a mineração no Brasil ocorre desde o rompimento da barragem de Fundão, no dia 5 de novembro de 2015, no município de Mariana, em Minas Gerais. A barragem integrava o Complexo Minerário Germano da empresa Samarco Mineração S.A, cujo capital é controlado paritariamente pelas corporações Vale S.A e BHP Billiton Brasil Ltda. ${ }^{2}$

De imediato, o desastre-crime ${ }^{3}$ da Samarco, foco deste artigo, resultou em 20 mortes e na liberação de aproximadamente 34 milhões de metros cúbicos de rejeitos minerários, que percorreram $663 \mathrm{~km}$ através dos Rios Gualaxo do Norte, Carmo e Doce, desembocando no litoral de Linhares, no Espírito Santo (ZHOURI et al, 2016).

O desastre provocou crises de abastecimento de água em várias cidades de Minas Gerais e do Espírito Santo, deixando um séquito de atingidos ao longo da Bacia do Rio Doce e no litoral capixaba, entre agricultores, assentados de reforma agrária e populações tradicionais como pescadores, ribeirinhos e povos indígenas. Os subdistritos de Bento Rodrigues e Paracatu de Baixo, em Mariana, e parte da sede do município de Barra Longa e o povoado de Gesteira, também em Barra Longa, foram significativamente atingidos pelos rejeitos, configurando territórios-arrasados e desterritorializando milhares de pessoas. ${ }^{4}$ Mais de dois anos após o desastre, grande parte dos atingidos deslocados compulsoriamente reside em casas alugadas, principalmente, em bairros urbanos de Mariana.

Este artigo parte da noção de biopolítica de Foucault (1985; 1999) para chegar na noção de necropolítica de Mbembe (2011), apontando para o poder ilimitado do segmento minerador, pela produção de desastres que submetem diferentes formas de vida e, mais especificamente o corpo-território, "ao poder da morte". No âmbito dessa bio(necro)política da mineração, a partir de

\footnotetext{
${ }^{2}$ A Samarco figura como a segunda maior empresa no mercado transoceânico de pelotas de minério de ferro e uma das maiores empresas exportadoras do país. O complexo minerário da empresa compreende mina de extração e indústria de beneficiamento primário de minério de ferro em Mariana-MG, três minerodutos, quatro usinas de pelotização e um terminal marítimo em Anchieta-ES (Disponível em: https://goo.gl/CswVpn. Acesso em: 11/02/2017).

${ }^{3}$ Os atingidos e os movimentos sociais, como o Movimento dos Atingidos por Barragens (MAB), defendem a utilização do termo "crime", culpável e imputável, como forma de responsabilizar, inclusive judicialmente, a Samarco/Vale/BHP Billiton e o Estado. Ao longo do artigo, utilizaremos indistintamente desastre (termo também teórico-conceitual) e desastre-crime.

${ }^{4}$ A população atingida em Mariana engloba não só as comunidades de Bento Rodrigues e Paracatu de Baixo, mas também de Paracatu de Cima, Pedras, Borba, Campinas, Camargos e Ponte do Gama.
} 
relatórios produzidos (PRISMMA, 2018; GREENPEACE; INSTITUTO SUSTENTABILIDADE E SAÚDE, 2017) e de alguns relatos de atingidos, destacamos os problemas de saúde vivenciados em Mariana (transtornos mentais) e Barra Longa (transtornos mentais, doenças respiratórias, alérgicas e contaminações).

O desastre é apreendido, neste artigo, como processo, logo, não limitado ao "eventocrítico" do rompimento, na medida em que as relações de poder e as respostas dadas, em termos de gestão dos danos, contribuem para prolongá-lo e reproduzi-lo no espaço-tempo e na vida dos atingidos (ZHOURI et al, 2016). Noutros termos: os desastres são processos "coletivos trágicos", que implicam em rupturas, imputando "perdas e danos súbitos e involuntários que desorganizam, de forma multidimensional e severa", a vida e, no caso, os modos de vida "de uma dada coletividade" (ZHOURI et al, 2016, p. 50). O desastre-crime da Samarco, portanto, não ocorreu no dia 5 de novembro de 2015, ele está ocorrendo desde então, é continuado, pois muitos dos seus efeitos são irreversíveis, vividos no cotidiano e não equacionáveis em termos econômicos.

Nesse quadro de análise, o desastre da Samarco é compreendido como fruto da mineração e do poder ilimitado do segmento empresarial minerador, em seu atrelamento às condições econômicas, sociais e políticas neoliberais. Tal poder se expressa na medida em que a Samarco não só produz desastre e danos como os administra, através da criação de uma Fundação privada, nomeada Renova, responsável por identificar, cadastrar e reparar as vítimas.

A Fundação Renova foi criada pelo Termo de Transação e Ajustamento de Conduta (TTAC), também conhecido como "Acordão", assinado em março de 2016 e homologado em maio do mesmo ano. O termo, celebrado entre as empresas rés Samarco/Vale/BHP Billiton, a Advocacia Geral da União e os governos dos estados de Minas Gerais e do Espírito Santo, estabelece os critérios de governança da Fundação então criada e propõe 41 programas socioeconômicos e socioambientais de reparação e compensação. Como expõe Onofre Alves Batista Júnior, Procurador e Advogado Geral do Estado de Minas Gerais, um dos "mentores" do TTAC, a opção pela criação de uma Fundação privada deve-se a "flexibilidade" e "expertise" possibilitada pela "atuação por meios privados". ${ }^{5}$ A Fundação é controlada pela Samarco, Vale e BHP Billiton, figurando, ao fim e ao cabo, desde a perspectiva dos movimentos sociais e dos atingidos, como um "anteparo" jurídico e simbólico das empresas culpadas pelo desastre (ROJAS; PEREIRA, 2017).

Nesse quadro, o artigo evidencia um confronto assimétrico entre os atingidos pelo desastre-crime da Samarco, suas narrativas corporificadas do dano, e a lógica empresarial de produção e de gestão do desastre. Nesse confronto, a própria noção de "atingido" passa a ser objeto de disputa, em "relação ao reconhecimento, leia-se legitimação, de direitos e de seus detentores" (VAINER, 2008, p. 40), ${ }^{6}$ face aos danos cotidianamente vivenciados. As ações da Samarco e da Fundação Renova, assim como o "paradigma clínico-laboratorial" pautado no nexo causal entre desastre e adoecimento, deslegitimam as narrativas dos atingidos, gerando "sofrimento social" (SILVA, 2004; 2017; OLIVEIRA, 2014). Embora o desastre alcance diferentes escalas espaciais,

\footnotetext{
${ }^{5}$ Informação retirada de transcrição da fala do Dr. Onofre Alves Batista, no Seminário jurídico "Dois Anos de Mariana", Escola Superior Dom Helder Câmara, Belo Horizonte, em 17/11/2017.

${ }^{6}$ A importância do uso do termo "atingido" (no lugar da categoria empresarial/institucional de "impactado") reside em sua construção como um elemento determinante de pertencimento, na luta cotidiana pela sobrevivência, frente aos danos dos grandes projetos de desenvolvimento, constituindo-se como um qualificativo catalizador de novas identidades, subjetividades e expressões políticas, a exemplo do Movimento dos Atingidos pela Vale e do Movimento dos Atingidos por Barragens (REBOUÇAS, 2000; VAINER, 2008).
} 
enfatizaremos neste artigo a escala do corpo, o corpo-território, afetado pelo desastre-crime e seus processos de desterritorialização.

\section{Bio(necro)política da mineração e sofrimento social: o desastre no corpo-território}

A biopolítica compreende uma tecnologia de poder centrada na população, no "corpo-espécie", na vida, inserindo-a "no domínio dos cálculos explícitos" (FOUCAULT, 1985). O biopoder é, portanto, o "direito de intervir [...] na maneira de viver, e no 'como' da vida [...]", mediante "regulamentações" que visam, sobretudo, controlar e otimizar a vida (FOUCAULT, 1999, pp. 295-296). Foucault afirma que o poder "incumbiu-se da vida", de cima a baixo (FOUCAULT, 1985), ou seja, "ele conseguiu cobrir toda a superfície que se estende do orgânico ao biológico, do corpo à população, mediante o jogo duplo das tecnologias de disciplina, de uma parte, e das tecnologias de regulamentação [biopolíticas], de outra" (FOUCAULT, 1999, p. 302).

Gaviria (2012, p. 8) ao tratar do projeto minerário da Alcoa em Juriti Velho, no Pará, aborda a ação "biopolítica" da mineradora a partir dos "processos de governamentabilidade que são acionados pela empresa [...], enquanto autoridade de governo, sobre a população e suas condições de vida". Nesse quadro de dominação empresarial, Acserald (2014) verifica a utilização tanto de técnicas "hard power", com militarizações e remoções, amparadas pela histórica aliança entre os setores econômicos e o Estado, como "soft power", com programas de responsabilidade social empresarial e ações compensatórias e mitigatórias.

As técnicas "soft power" agem no plano das subjetividades coletivas, enredando a crítica social e incorporando-a pro domo sua, a fim de controlar e gerir o "risco social"7, favorecendo a aceitação dos danos, a naturalização da "lógica do sacrifício" e a adequação dos territórios às necessidades do capital extrativo (WANDERLEY, 2009; ARÁOZ, 2014; ACSELRAD, 2014; GAVIRIA, 2012; 2015).

Para Svampa (2016, p. 372), as empresas mineradoras, pelo poder que exercem nos territórios em que se instalam, constituem "atores sociais totais". Nessa perspectiva, a despeito da imputação de danos aos territórios, no plano das relações micropolíticas em Mariana, o poder da Samarco pode ser conjecturado por meio das manifestações pelo retorno das atividades minerárias, levadas a cabo pelo movimento local "Justiça sim, desemprego não \#ficasamarco", e da discriminação dos atingidos.

De acordo com a Pesquisa sobre a Realidade de Saúde Mental (PRISMMA, 2018), 89,8\% dos atingidos (percentuais com base numa amostragem de 225 pessoas atingidas maiores de 18 anos) declararam já ter sofrido algum tipo de discriminação em Mariana, na medida em que são culpabilizados pelo não retorno das operações da Samarco e, por conseguinte, pelo desemprego. A discriminação sofrida pelos atingidos deslocados compulsoriamente para Mariana e a atuação do movimento "Justiça sim, desemprego não" devem ser compreendidas em face da presença

\footnotetext{
${ }^{7} \mathrm{O}$ "risco social" resulta da falta de consentimento da sociedade, que pode afetar a imagem e a reputação da empresa, assim como suas operações (GAVIRIA, 2015).

${ }^{8}$ Em novembro de 2015 e março de 2016 centenas de pessoas vestindo camisas brancas com os dizeres do movimento "Justiça sim, desemprego não \#ficasamarco", realizaram manifestações em prol da manutenção da empresa em Mariana (DO VALE; LOPES, 2015).
} 
histórica da mineração na região, que construiu econômica, política e subjetivamente (através, inclusive, dos discursos de "geração impostos", "emprego" e "desenvolvimento") relações de dependência e de poder hierárquicas. Grandes mineradoras, como a Samarco/Vale/BHP Billiton, dispõem de mecanismos e estratégias de poder que associam discurso e práticas, condições técnicas, econômicas, sociais e políticas, desdobrando seus efeitos normalizadores e produtivos na vida social, no nível mais íntimo das subjetividades.

Na perspectiva deste artigo, da mesma forma que podemos falar de uma biopolítica do segmento minerador, podemos falar de uma necropolítica do setor, produtor não só minérios, como também de riscos e desastres. Para Mbembe (2011), desde o período colonial vivenciamos, não só uma biopolítica, mas, sobretudo, uma necropolítica, pois o foco das tecnologias de poder encontra-se na "submissão da vida ao poder da morte" (MBEMBE, 2011, pp. 74-75). O "necropoder" envolve "a capacidade de definir quem tem importância e quem não a tem, quem está desprovido de valor e pode ser facilmente substituído e quem não" (MBEMBE, 2011, p. 46 tradução própria). Os "corpos matáveis" e os territórios passíveis de destruição são racializados, socialmente e historicamente vulnerabilizados e subalternizados. Como no caso do desastre da Samarco, as principais comunidades atingidas pela lama de rejeitos eram predominantemente compostas por negros e pardos, evidenciando uma carga desproporcional de riscos e danos sobre grupos étnicos mais vulneráveis (WANDERLEY, 2015).

O rompimento da barragem de rejeitos em Mariana resultou, de imediato, em 19 mortes e um aborto. Entre operários terceirizados da Samarco e moradores do subdistrito de Bento Rodrigues, muitas vidas foram ceifadas, tornadas "sem valor", transformadas "em vida nua" (AGAMBEN, 2010), dada a expropriação mais absoluta: a expropriação da própria vida. Entretanto, o número de mortes no contexto do desastre-crime se atualiza, como relata uma atingida: "Agora, se a gente for fazer, se for contar de novo as pessoas que morreram, tem mais. Aqui, o D. mesmo que suicidou, pra gente, foi por causa disso. [...] Se você for recalcular hoje, já morreram mais pessoas, senhores, principalmente, de tristeza, de depressão" (Entrevista com A., atingida de Gesteira, Barra Longa, em 3/02/2018).

Mendiola (2009 apud HAESBAERT, 2014) complexifica o princípio biopolítico "'fazer viver, deixar morrer'", alterando-o "para 'fazer viver, fazer deixar morrer'". Esse "fazer deixar morrer", ou melhor, esse "fazer morrer", nos conduz a necessidade de compreensão dos dispositivos pelos quais os desastres, assim como as mortes que Ihes acompanham, são sistematicamente produzidos. No cerne do desastre da Samarco, encontra-se o que podemos nomear como "capitalismo de desastre" (KLEIN, 2008), já que a produção de riqueza é acompanhada sistematicamente pela produção de riscos, danos e catástrofes, principalmente no âmbito da racionalidade neoliberal (BECK, 2011; KLEIN, 2008). Os desastres são derivados, portanto, em grande parte, do desenvolvimentismo, "do poderoso sistema técnico-científico" que se impõe modernocolonialmente (PORTO-GONÇALVES, 2006).

Como menciona Archambault (2011) a partir de sua leitura de Mbembe, a "economia da morte" não pode ser dissociada das relações de produção e de poder. Logo, nessa necropolítica da mineração não podemos deixar de mencionar o papel basilar do setor minerário na indústria moderna, "e em particular na indústria da guerra" (ARÁOZ, 2014, p. 63). Ademais, é importante destacar que a mineração figura como um dos setores da economia que mais mata e mutila trabalhadores no Brasil (XAVIER; VIEIRA, 2016), ao mesmo tempo em que converte, em sua violên- 
cia crônica, "territórios em áreas de sacrifício, [...] onde também os corpos e as vidas mesmas tornam-se descartáveis e sacrificáveis" (SVAMPA, 2016, p. 373).

Não obstante, observa-se a banalização da morte e a naturalização do fato da mineração destruir territórios e "produzir a morte" de diferentes formas e modos de vida, em nome do desenvolvimento. A fala do então prefeito de Mariana, Duarte Júnior, é sintomática: "A questão é que a gente precisa se preocupar com o lado econômico da cidade... Um avião, quando cai, também mata pessoas e a empresa não espera para voar no outro dia" (EXAME.COM, 15/03/2016). Como menciona Haesbaert (2014, pp. 207-208), nossa época é marcada tanto pela perda do "poder sobre a vida", quanto pela banalização da morte, "ou seja, é um tempo moldado não só pela 'bio', mas também pela 'tanatopolítica', época em que prolifera todo tipo de risco, incerteza e/ou insegurança $[\ldots] "$.

No âmbito dessa necropolítica da mineração, podemos aludir aos dados da "Pesquisa sobre a Realidade de Saúde Mental (PRISMMA)" das famílias atingidas pelo rompimento da Barragem de Fundão, em Mariana, realizada pelo Núcleo de Pesquisa Vulnerabilidades e Saúde (NAVeS) da Faculdade de Medicina da UFMG. ${ }^{9}$ Conforme a PRISMMA (2018), 28,9\% da população amostral (percentuais com base numa amostragem de 225 pessoas atingidas maiores de 18 anos) foi diagnosticada com depressão, percentual cinco vezes maior do que o descrito pela Organização Mundial de Saúde (OMS) para a população brasileira; 12\% dos atingidos foram identificados com transtorno de estresse pós-traumático, número comparável ao verificado em outros desastres, como o de Fukushima; 32\% dos entrevistados foram diagnosticados com transtorno de ansiedade generalizada, índice três vezes maior que o aferido para a população geral e em 16,4\% dos atingidos foi constatado "risco de suicídio" (desejo de morte, ideação suicida, tentativas de suicídio).

Os dados sobre a saúde mental de crianças e adolescentes (entre 10 e 17 anos) também apontam para a relação entre o desastre-crime e doenças psicopatológicas: 82,9\% dos respondentes (percentual com base numa amostragem de 46 entrevistados) foram rastreados positivamente para transtorno de estresse pós-traumático; 39,1\% dos entrevistados foram rastreados positivamente para transtorno de ansiedade e 39,1\% (mesmo percentual) para depressão. Entre os sintomas relacionados ao transtorno depressivo, nessa faixa etária, destacam-se o "pensamento de morte" e a "ideação suicida" (PRISMMA, 2018).

Em Barra Longa, o Greenpeace e o Instituto Saúde e Sustentabilidade (2017, p. 32) realizaram um estudo com base na "identificação por autoavaliação das percepções das famílias [...] quanto aos efeitos [do desastre] na saúde". Antes de entrar nos dados do estudo supracitado, é importante esclarecer que parte da sede de Barra Longa foi destruída pelos rejeitos, o que inclui o centro e várias áreas, com casas e quintais produtivos, ao longo do Rio do Carmo, que margeia a cidade. A Fundação Renova/Samarco retirou o rejeito das partes centrais da cidade, reformou residências e comércios afetados, assim como a praça principal, produzindo uma "descontaminação", principalmente, visual e simbólica da cidade.

O rejeito retirado das áreas centrais foi depositado no Parque de Exposições de Barra Longa e utilizado para calçar ruas da cidade e reparar estradas de terra do município. Assim, terri-

\footnotetext{
${ }^{9}$ A população atingida considerada na referida pesquisa engloba as comunidades de Bento Rodrigues, Paracatu de Baixo, Paracatu de Cima, Borba, Pedras, Campinas e Ponte do Gama.
} 
tórios periféricos não afetados, de imediato, pelo rompimento de Fundão, foram atingidos, posteriormente, pelas obras da Fundação Renova, configurando novas situações de "injustiça ambiental" no contexto do desastre-crime. Como menciona uma moradora que ainda reside no Parque de Exposições de Barra Longa, na periferia da cidade: "O pessoal lá [do centro da cidade] não podia ficar com esse barro, com o rejeito. Mas esqueceram que a gente morava aqui" (Entrevista com C., atingida de Barra Longa, em 2/03/2018). ${ }^{10}$

Nesse contexto, para além da exposição prolongada à lama do desastre, Barra Longa sofreu com a exposição ao "pó proveniente da lama seca, exacerbada pelas obras de reconstrução da cidade" (GREENPEACE; INSTITUTO SAÚDE E SUSTENTABILIDADE, 2017, p. 89). Conforme o Greenpeace e o Instituto Saúde e Sustentabilidade (2017, p. 89), "a bacia aérea da cidade se tornou tóxica", os níveis de material particulado, em outubro de 2016, "chegaram a atingir níveis de concentração altos", ultrapassando os padrões de qualidade do ar preconizados pela OMS. Nesse cenário, 40\% da população amostral (223 famílias/507 indivíduos) afirmou sofrer de problemas respiratórios (o percentual alcançou $60 \%$ na faixa etária de 0 a 13 anos, considerando o total de 72 crianças rastreadas nas famílias respondentes); 15,8\% declararam sofrer de afecções de pele; e $11 \%$ de transtornos mentais e comportamentais (GREENPEACE; INSTITUTO SAÚDE E SUSTENTABILIDADE, 2017). Da população entrevistada, 77,9\% apresentaram, desde o início do desastre, sintomas físicos variados, alguns deles, embora possam estar presentes em diversas afecções, podem ser indicativos de quadros de intoxicação por alguns metais (GREENPEACE; INSTITUTO SAÚDE E SUSTENTABILIDADE, 2017). Exames realizados em março de 2017, para quantificação total de metais, em onze moradores do município, cujos sintomas físicos são significativos de outros quadros clínicos em Barra Longa, evidenciaram altos níveis de níquel e, em alguns casos, também de arsênio no sangue. D., hoje com quatro anos de idade, apresenta problemas respiratórios e alérgicos e foi uma das onze pessoas que realizaram o exame: "[...] ela não é reconhecida como atingida, porque a empresa diz que a lama não é tóxica. [...] Ela está contaminada. A médica de São Paulo disse que eu tenho que me mudar de Barra Longa, porque é muito grave, minha filha pode morrer [...]" (Entrevista com A, atingida Gesteira, Barra Longa, em 3/02/2018).

Enquanto a empresa afirma que os rejeitos eram "inertes", ou seja, não continham metais pesados que pudessem causar danos à saúde, diversos relatórios e laudos apontam para a presença de altos níveis de metais pesados, entre outras substâncias químicas nos ecossistemas afetados, já que "o derramamento de rejeitos causou o revolvimento e aumento da biodisponibilidade de uma série de componentes tóxicos" (GREENPEACE; INSTITUTO SAÚDE E SUSTENTABILIDADE, 2017, p. 89). Nesse quadro, não só a Samarco e a Fundação Renova, como também o "paradigma clínico-laboratorial" (SILVA, 2004; 2017) convencional, não admitem o nexo causal entre adoecimento e desastre.

Em assembleia em Barra Longa, em 16 de abril de 2018, para discussão da questão da saúde, a Doutora Evangelina da Motta Vormittag, diretora do Instituto Saúde e Sustentabilidade, declarou que não é possível afirmar que os metais pesados constatados nos exames toxicológicos

\footnotetext{
${ }^{10}$ No Parque de Exposição, localizado próximo a entrada da cidade, residiam 8 famílias, já em situação de vulnerabilidade social. Em 30 de agosto de 2017 foi firmado Termo de Acordo para retirada dessas famílias da área do Parque. Entretanto, uma das famílias permaneceu no local, dado ao apego ao território, não obstante os inúmeros danos vivenciados.
} 
dos moradores de Barra Longa têm sua origem na exposição aos rejeitos do desastre. Na mesma medida, o estudo produzido para Mariana, embora rastreie a existência de doenças psicopatológicas em crianças e adolescentes, trazendo índices exorbitantes e anormais, também afirma a impossibilidade de estabelecer o nexo causal entre a exposição ao rompimento da barragem e a relevante morbidade psíquica encontrada (PRISMMA, 2018, p. 68).

Toda a discussão se reduz, assim, ao âmbito do "risco", o desastre se torna tão somente um "fator de risco", na linguagem técnica e clínica/biomédica. Entretanto, para a população atingida, os riscos não são riscos, e sim danos, doenças, dores físicas. Nesse quadro, não basta sentir, é necessário provar, submeter-se aos "órgãos sensoriais" da hard sciences - laudos técnicos, experimentos, exames, medições (BECK, 2011; OLIVEIRA, 2014). Conforme Beck (2011, p. 76), a "insistência em torno da prova causal estrita" é inadequada para os riscos da modernização, produzindo desresponsabilização, pois sob a alegação de causas diversas, da "insuficiente" prova causal, nada é causa.

Telma Camargo Silva $(2004 ; 2017)$ ao tratar do desastre radioativo de Goiânia, aponta para o "paradigma clínico-laboratorial" que só reconhece o "sofrimento matemático/métrico" que pode ser medido e provado, deslegitimando as narrativas de sofrimento das vítimas. Logo, o desastre é vivenciado desde a escala do corpo, na medida em os atingidos recordam e reatualizam o desastre em suas inscrições corporais. Entretanto, o sofrimento "não é objetivado num local específico no corpo, pois a dor, embora criada e/ou gerada no corpo, é também constituída pelas relações do corpo com as forças sociais e com as contradições sociais presentes nas ideologias médicas" (DELVECCHIO GOOD et al, 1994 apud SILVA, 2017, p. 221), assim como na relação do corpo com o território contaminado e/ou destruído, marcada por processos desterritorialização.

A desterritorialização é aqui apreendida nos temos de Haesbaert (2007b, p. 20) para além do deslocamento físico-compulsório, como perda do "controle' e/ou" da "segurança" nos territórios (HAESBAERT, 2007b, p. 20), como "[...] exclusão, privação, [destruição, contaminação], e/ou precarização [...]" territorial (HAESBAERT, 2007a, p. 315). Conforme Haesbaert (2007b, p. 20), processos de desterritorialização afetam, sobretudo, os grupos subalternizados, numa imbricação entre desterritorialização e imputação de uma "territorialização precária."

O desastre, portanto, nos remete a destruição do corpo-território, corpo que está no território e é território, evidenciando mais uma das dimensões bio(necro)políticas da mineração, manifesta na expropriação e/ou destruição dos próprios meios que nos fazem corpos: a água, a terra, o ar, em suma, o território.

Nessa perspectiva, é importante reforçar que a noção de "atingido" abrange não somente as coletividades que sofreram com o deslocamento físico-compulsório em função dos rejeitos, mas todos aqueles que mesmo permanecendo em seus territórios, foram também desterritorializados, na medida em que tiveram suas condições ambientais deterioradas e suas condições de existência e de reprodução social esfaceladas. ${ }^{11}$ Ademais, é justamente por continuarem em seus

\footnotetext{
${ }^{11}$ Nesse cenário de perdas, há milhares de atingidos: aqueles que perderam sua segurança ontológica, seus quintais produtivos (como na sede urbana de Barra Longa); suas condições de saúde em função da precarização e contaminação dos territórios; seus meios de reprodução econômica e social; aqueles que morando próximo aos territóriosarrasados, perderam seus equipamentos coletivos, as redes de vizinhança e de sociabilidade e, hoje, são obrigados a conviver com um cenário de catástrofe (como os moradores de Paracatu de Cima, já que Paracatu de Baixo foi destruído); só para citar algumas situações.
} 
territórios de origem, não obstante os danos do desastre, que determinados grupos sociais estão submetidos não só a condições de risco e insegurança, mas a ambientes insalubres, pela imposição da convivência com o rejeito, presente no solo, na água e no ar.

Com uma abordagem restritiva de "impactado", a Samarco/Renova só reconhece, de antemão, aqueles cujas propriedades foram afetadas/arrasadas pela lama. Assim, os atingidos que não sofreram com o deslocamento físico passam a ter que "provar", em diferentes instâncias de negociação, que são "atingidos" pelo desastre-crime. Contrapondo essa visão, Marino D’Ângelo, atingido de Paracatu de Cima, afirma: "A Samarco tá medindo o tanto que a pessoa é atingida de acordo com o quanto a lama sujou o que ele tem [suas propriedades e bens materiais]. Só que não é assim. Atingido é aquele que a lama sujou a vida. E, nesse sentido, eu tô afogado na lama" (BRASIL DE FATO, novembro de 2017, p. 2).

Na concepção de Silva (2017, p. 23), "as narrativas de dor dos sobreviventes expressam mais do que o sofrimento das consequências materiais, físicas [...]. A dor é engendrada também [...] na busca da afirmação e legitimidade de suas falas". Logo, para a autora, o "sofrimento social" e a dor dos sobreviventes são engendrados no âmbito de um contexto conflitual. Nesses termos, o "sofrimento social" dos atingidos pelo desastre-crime da Samarco não decorre somente da dor física, do adoecimento, mas também dos conflitos instaurados; da discriminação; do nãoreconhecimento da condição de atingido e de sua submissão constante ao ônus da prova; da insegurança quanto ao futuro; da ausência, insuficiência ou provisoriedade das medidas mitigatórias adotadas; dos processos morosos de negociação instaurados, que geram um grande desgaste físico e emocional; da imposição da espera e das inúmeras perdas sofridas: perda/destruição do território de origem, das condições de reprodução social, do controle e da segurança nos territórios, do convívio comunitário e de vidas.

\section{Considerações finais}

A mineração encontra-se na base da ordem moderno-colonial capitalista, colocando em manifesto velhas e novas formas de dominação e dependência (ARÁOZ, 2014). Como afirma Aráoz (2009), a mineração é geradora de "violência colonial", de caráter endêmico, que decorre da violação e negação sistemática de direitos e da destruição e/ou inviabilização dos meios e dos modos de vida de determinados grupos subalternos.

O desastre da Samarco, portanto, não deve ser visto como "acidente", mas como fruto da mineração e do poder desmedido do segmento empresarial minerador, em seu atrelamento às condições econômicas, sociais e políticas neoliberais que propiciam a reprodução ampliada do capital, pela via da "espoliação" (HARVEY, 2005).

A racionalidade desenvolvimentista neoliberal inscreve o desastre no território e no corpo de seus habitantes. No âmbito dessa bio(necro)política da mineração, o desenvolvimento figura como um leitmotiv, uma ideologia que torna os "sujeitos matáveis", em nome do "bem comum", do crescimento econômico e da geração de empregos.

Por traz das manifestações clínicas, das doenças, encontra-se a degradação dos meios que nos fazem corpos (água, ar, terra) e, por conseguinte, vale dizer, do próprio do território, em 
sua dimensão não só material, mas também simbólica. O desastre, portanto, na medida em que se prolonga no espaço-tempo, se atualiza no corpo dos atingidos, pois a "experiência do desastre funde a temporalidade na persistência do sofrimento como memória e como realidade vivida no presente" (SILVA, 2017, p. 25).

O "sofrimento social" decorre do processo conflitual do desastre, em que os atingidos são instados a provar que são atingidos, pois suas narrativas são constantemente desautorizadas, seja pelo paradigma técnico, clínico-laboratorial - que só legitima a dor que pode ser medida e provada em seu nexo causal com o desastre - seja pela tradução de "impactado" da empresa, que só reconhece de antemão aqueles que sofreram com o deslocamento físico-compulsório, submetendo todos os demais atingidos que também foram desterritorializados ao ônus da prova. O desastre e o sofrimento social dele advindo, portanto, persiste nas relações de poder instauradas na gestão dos danos, na perpetuação das perdas, nas violações de direitos, na imposição da espera, nos processos de desterritorialização decorrentes da destruição, da contaminação e da precarização dos territórios.

Ademais, é importante mencionar que o desastre não rompe/colapsa nem o dispositivo empresarial, a Samarco, nem o que podemos chamar de "capitalismo de desastre" (KLEIN, 2008). Uma "deseconomia de escala", um desastre, origina novas economias de escala, novas fontes de lucratividade (RODRIGUES, 1998), promovendo a apropriação privada e mercadológica do desastre, ao acionar todo um complexo técnico, midiático, de engenharia, de construção, de consultorias etc.. Assim, o desastre figura, para alguns, como uma fonte de lucros e, para a maioria, como uma fonte de destruição, com danos mais brutais para os mais vulneráveis. Nesse quadro, a empresa prossegue com seu poder ilimitado, evidenciando sua "resiliência" ao desastre, já que Vale e a BHP, proprietárias da Samarco, seguem com lucros da ordem de bilhões de dólares. Devidamente assegurada contra o risco de rompimento de Fundão, a Vale e BHP Billiton receberam um seguro, cujo valor é mantido em sigilo pelas empresas, para compensar a perda de receita e os chamados "lucros cessantes", assegurando seu patrimônio (RUSSAU, 2017). Nos territórios locais, que aportam as atividades minerárias, tal resiliência só pode ser compreendida na medida em que o segmento privado excede sua função produtiva, voltada para a geração de lucros, sendo capaz de criar relações de dependência e de produzir e influenciar determinadas relações sociais, subjetividades, formas de viver e de agir.

Para sanar os danos da mineração, a Samarco alega a necessidade de mais mineração, ou seja, do retomo de suas atividades extrativas, tendo conseguido, em dezembro de 2017, a Licença Prévia (LP) e a Licença de Instalação (LI) da Cava da Alegria Sul (nova proposta técnica para disposição de rejeito, em substituição ao antigo sistema de barragens). ${ }^{12}$ Entretanto, mudanças nas técnicas de acondicionamento de rejeitos, só deslocam, sem resolver, a contradição mortal dos sistemas sociais, cuja dinâmica está baseada no crescimento ilimitado dos bens materiais. Vivemos, pois, sob uma lógica da gestão dos riscos e dos desastres, que busca controlar e administrar seus efeitos, sem atacar suas causas.

\footnotetext{
12 A técnica utilizada na contenção de rejeitos pela Samarco é denominada de "barragem com alteamento a montante". A Samarco solicitou as licenças ambientais para retomada das operações da empresa, propondo a utilização de uma antiga cava de mineração, a Cava Alegria Sul, para disposição de rejeitos, em substituição ao antigo sistema de barragens. Para a retomada das operações faltam a licença de operação da Cava (LO) e a Licença de Operação Corretiva (LOC) (Informações pautadas em Audiência Pública do Licenciamento Operacional Corretivo do Complexo de Germano, em Mariana, em 7/12/2017).
} 
Os desastres, portanto, são produzidos sistematicamente, expondo um ciclo de afetações que não termina, pelo contrário, se expande sob o baluarte do desenvolvimentismo e da gestão, negociação e controle neoliberal dos danos. Nesse contexto, o desastre prossegue em sua gestão, na medida em que a catástrofe se prolonga e se reproduz nos territórios, desencadeando conflitos de onde insurgem, "sub-alternativamente", possibilidades para a $r$-existência e para o não-conformismo.

Aprovado pela Comissão Científica do III CONGEO - Congresso Brasileiro de Geografia Política, Geopolítica e Gestão do Território Universidade Federal Fluminense - Niterói (RJ), 2018 
Referências

ACSELRAD, Henri. Estratégias empresariais e militares de controle de território. Confluências Autoritárias. Le monde diplomatique, 5/05/2014. Disponível em: <http://goo.gl/blsmhL.> Acesso em: 12 nov. 2015.

AGAMBEN, Giorgio. Homo Sacer. O poder soberano e a vida nua I. 2 ed. Belo Horizonte: Editora UFMG, 2010b.

ALTVATER, Elmar. O Preço da Riqueza. São Paulo: Editora da USP, 1995.

ARÁOZ, Horácio M. Auge minero y dominación neocolonial en América Latina. Ecología política de las transformaciones socioterritoriales neoliberales. In: 27 CONGRESO DE LA ASOCIACIÓN LATINOAMERICANA DE SOCIOLOGÍA, 2009, Buenos Aires. Anais... Buenos Aires: Acta Académica, 2009.

Territorios y cuerpos en disputa: extractivismo minero y ecologia política de las emociones. Intersticios. v. 8, n. 1. p. 56-71, 2014.

ARCHAMBAULT, Elisabeth F. Introducción. In: MBEMBE, Achille. Necropolítica. Editorial Melusina, S.L., 2011.

BRASIL DE FATO. Tragédia de Mariana. 2 anos depois, o que (não) aconteceu?. Especial. Belo Horizonte, novembro de 2017.

BECK, Ulrich. Sociedade de Risco. Rumo a outra modernidade. Tradução de Sebastião Nascimento. São Paulo: Editora 34, 2011.

CORONIL, Fernando. Natureza do Pós-colonialismo: do eurocentrismo ao globocentrismo. In: LANDER, Edgardo (Org.). Colonialidade do saber: eurocentrismo e ciências sociais. Perspectivas Latino-americanas. Buenos Aires: Clacso, 2005.

DO VALE, João H.; LOPES, Valquíria. Em protesto, grupo de moradores de Mariana defende mineradora: "Justiça sim, desemprego não". Estado de Minas, 17/11/2015. Disponível em: <https://goo.gl/it46vn>. Acesso em: 28 fev. 2017.

EXAME.COM. Com economia agonizante, Mariana quer volta de Samarco, 15/03/2016. Disponível em: <https://goo.gl/R35Vml>. Acesso em: 27 fev. 2017.

FOUCAULT, Michel. História da Sexualidade I: A vontade de saber. Rio de Janeiro: Edições Graal, 1985.

Em Defesa da Sociedade. São Paulo: Martins Fontes, 1999.

GAVIRIA, Edwin A. Muñoz. A "licença social para operar" na mineração industrial e a produção empresarial da dominação. In: 39 ENCONTRO ANUAL DA ANPOCS, 2015, Caxambú-MG. Anais... Caxambu: ANPOCS, 2015. Disponível em: <http://goo.gl/6AdZpa>. Acesso em: 1 mar. 2018.

Biopolítica empresarial na Amazônica brasileira: estratégias de sustentabilidade e responsabilidade social da mineradora Alcoa em Juruti, estado do Pará. In: 6 ENCONTRO NACIONAL DA ANPPAS, 2012, Belém-PA. Anais... Belém: ANPPAS, 2012. 
GREENPEACE; INSTITUTO DE SAÚDE E SUSTENTABILIDADE. Avaliação dos riscos em saúde da população de Barra Longa/MG afetada pelo desastre. Março de 2017.

HAESBAERT, Rogério. O mito da desterritorialização. Do "Fim dos Territórios" à Multiterritorialidade. 3 ed. RJ: Bertrand Brasil, 2007a.

Território e Multiterritorialidade: um debate. GEOgraphia, Rio de Janeiro, ano IX, n. 17, 2007b.

Viver no Limite. Rio de Janeiro: Bertrand Brasil, 2014.

HARVEY, David. O Novo Imperialismo. 2. ed. São Paulo: Edições Loyola, 2005.

KLEIN, Naomi. A doutrina do Choque: a ascensão do capitalismo de desastre. Tradução Vania Cury. Rio de Janeiro: Nova Fronteira, 2008.

MALERBA, Julianna. Para quê um novo código mineral? In: MALERBA, Julianna; MILANEZ, Bruno; WANDERLEY, Luiz Jardim (Org.). Novo Marco Legal da Mineração no Brasil: Para quê? Para quem?. Rio de Janeiro: Fase, 2012.

MBEMBE, Achille. Necropolítica. Editorial Melusina, S.L., 2011.

RODRIGUES, Arlete Moysés. Produção e Consumo do e no espaço. Problemática Ambiental Urbana. São Paulo: Hucitec, 1998.

OLIVEIRA, Raquel. O dano e a prova, o risco e a dor: sofrimento social na luta dos moradores do Bairro Camargos. In: 29 REUNIÃO BRASILEIRA DE ANTROPOLOGIA, 2014, Natal. Anais... Natal: RBA, 2014.

PORTO-GONÇALVES, Carlos Walter. A Globalização da Natureza e a Natureza da Globalização. Rio de Janeiro: Civilização Brasileira, 2006.

PRISMMA. Pesquisa sobre a saúde mental das famílias atingidas pelo rompimento da barragem de Fundão em Mariana. Belo Horizonte: Corpus, 2018.

REBOUÇAS, Lídia M. O Planejado e o vivido. O reassentamento de famílias ribeirinhas no ponto de Paranapanema. São Paulo: Annablume: Fapesp, 2000.

ROJAS, Cláudia M. O.; PEREIRA, Doralice B. O rompimento da barragem de Fundão/MG: reflexões preliminares sobre o modus operandi da Samarco (Vale/BHP Billiton). In: 41 ENCONTRO ANUAL DA ANPOCS, 2017, Caxambu. Anais... Caxambu: ANPOCS, 2015. Disponível em: <https://goo.gl/EyQiPE>. Acesso em: 1 mar. 2018.

RUSSAU, Christian. A nebulosa saga das indenizações bilionárias que a Samarco recebe "por lucros cessantes". Combate Racismo Ambiental, 12/11/2017. Disponível em: https://goo.gl/Sj9v4P. Acesso em: 25 mai. 2017.

SILVA, Telma C. Desastre como processo: saberes, vulnerabilidade e sofrimento social no caso de Goiânia. In: ANNETTE, Leibing (Org.). Tecnologias do corpo: uma antropologia das medicinas no Brasil. Rio de Janeiro: NAU Editora, 2004.

Silêncios da dor: enfoque geracional e agência no caso do desastre radioativo de goiânia, Brasil. Iberoamericana, v. 46, n. 1, pp. 17-29, 2017. 
SVAMPA, Maristella. Debates Latinoamericanos. Indianismo, desarrollo, dependência y populismo. 1. Ed. Cidad Autónoma de Buenos Aires: Edhasa, 2016.

VAINER, Carlos. Conceito de "Atingido": Uma revisão do Debate. In: ROTHMAN, Franklin Daniel. Vidas alagadas: conflitos socioambientais, licenciamento e barragens. Viçosa, MG: Ed. UFV, 2008.

WANDERLEY, Luiz Jardim. Deslocamento compulsório e estratégias empresariais em áreas de mineração: um olhar sobre a exploração de bauxita na Amazônia. Revista Ideas. v. 3, n. especial, p. 475-509, 2009.

Indícios de Racismo Ambiental na Tragédia de Mariana: resultados preliminares e nota técnica, 20/11/2015. Disponível em: <https://goo.gl/xr1wcQ>. Acesso em: 1 mar. 2018.

XAVIER, Juliana B.; VIEIRA, Larissa P. de Oliveira. O trabalho e seus sentidos: a destruição da força humana que trabalha. In: MILANEZ, Bruno; LOSEKANN, Cristiana (Org.). Desastre no Vale do Rio Doce. Antecedentes, impactos e ações sobre a destruição. Rio de Janeiro: Folio Digital: Letra e Imagem, 2016.

ZHOURI, Andréa et al. O Desastre de Mariana: colonialidade e sofrimento social. In: ZHOURI, Andreá; BOLADOS, Paola; CASTRO, Edna (Org.). Mineração na América do Sul. Neoextrativismo e lutas territoriais. São Paulo: Annablume, 2016. 